\title{
Characterization of a Glow Discharge Ion Source for the Mass Spectrometric Analysis of Organic Compounds
}

\author{
D. Carazzato and M. J. Bertrand \\ Regional Center for Mass Spectrometry, Department of Chemistry, University of Montréal, Montréal, Canada
}

\begin{abstract}
A glow discharge ion source has heen constructed for the mass spectrometric analysis of organic compounds. Characterization of the source has been made by studying the effect of pressure and discharge current on ionic distributions by anodic ion sampling along the discharge axis. Ion and electron densities and electronic temperatures have been calculated by using the single Langmuir probe technique to correlate the extraction efficiency with measured ion distributions and gain some insight into the ionization of organic molecules. The spectra obtained for several classes of organic compounds show that formation of parent-molecular ions by proton transfer, resulting partly from the background water molecules, is a major low energy process while charge transfer, Penning ionization, and electron ionization are probably responsible for the fragmentation observed. The spectra result from the simultaneous occurrence of high and low energy reactions, and their structural information content is very high, yielding both molecular and extensive fragment ion information. The glow discharge ion source has proved to be essentially maintenance-free, easy to operate, stable, and can be used at reasonable mass resolution (up to 7000). The source also provides picogram range detection limits and has a linear response range of about six orders of magnitude, which makes it an interesting ion source for routine analysis. Preliminary work conducted with chromatographic interfaces indicates that its use can be easily extended to both gas and liquid chromatography. (J Am Soc Mass Spectrom 1994, 5, 305-315)
\end{abstract}

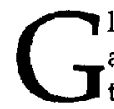
low discharge devices have been mainly used as hollow cathode lamps for producing characteristic emission lines in spectroscopic techniques, and since their introduction in mass spectrometry in the early 1970s [1-10], they have been used extensively in inorganic analysis [11-13]. Some of these applications involve the analysis of thin metallic films [14], bulk materials, and semiconductors [15-18]. Although their design can differ from one application to another, they may all be represented by a classical gas tube in which one of the electrodes (cathode) is made of the sample material and the other (anode), of lesser importance, floats at the source block potential or is simply grounded. The tube is usually filled with a rare gas at a pressure in the range of 0.01 to 1 torr. In the case of a direct current discharge, a potential of a few hundred volts, negative to anode, is applied to the cathode to initiate and maintain the discharge, which usually involves a current density at the cathode ranging from 0.1 to $10 \mathrm{~mA} / \mathrm{cm}^{2}$. The discharge appears nonhomogenous, showing glowing regions and dark spaces [19], and, depending on the source dimensions

Address reprint requests to $M$. J. Bertrand, Regional Center for Mass Spectrometry, Department of Chemistry, University of Montréal, P.O. Box 6128, Station A, Montréal, Canada H3C $3 J 7$. and operating conditions, it may or may not leave enough space for a positive column to develop. In most applications, however, the discharge is restricted to the cathode fall and the negative glow. The technique uses positive ions formed and accelerated through the cathode fall to bombard the cathode to eject atoms and particles. This process, called sputtering [20], is followed by diffusion of the neutrals toward the negative glow. Ionization mostly takes place in this region by Peruing ionuzation $[21,22]$ when metastable atoms in the discharge collide with sputtered particles, producing positive ions and electrons with a range of energies that depends on the nature of the discharge gas. Because the electrons in the glow discharge have a kinetic energy distribution ranging from slow to fast $(0.3-25 \mathrm{eV})$ [23], electron ionization (EI) may also occur but its contribution to ionic production is usually much less than the Penning process. Except for its two boundaries, where sharp potential barriers are observed, the glow is a relatively field-free region [24] and, thus, ion diffusion may lead to ion losses by recombination with slow-moving electrons in the glow or at the walls or changes in ion identity by ion-molecule reactions such as proton exchange and clustering. The ions observed in the mass spectrum are those arriving at the anode sheath in the vicinity of the 
electrode aperture. They are accelerated across the sheath and then mass analyzed. Ions formed by collisions with high energy electrons in the cathode fall region will not be observed in the mass spectrum as they will not be extracted from the discharge. Although the use of glow discharge sources mainly concerns inorganic analysis, in which they are used to both sputter and ionize the analytes, they have also been used for the analysis of organic compounds. Tanabe and Winefordner [25] have used the afterglow of an electrical discharge under reduced pressure (1-10 torr) to generate metastable argon, helium, and nitrogen to study the excitation and fluorescence of benzene and anthracene, while Anderson et al. [26] have used the same technique as an ionizing medium. Unusual reagent gases for chemical ionization known to rapidly deteriorate the source filament, such as nitrogen oxides [27] or methanol [28], performed successfully in a glow discharge device, providing mass spectra similar to those obtained by the filament method but with the advantage that the glow discharge source was essentially maintenance-free. Townsend $[29,30]$ and corona [31] discharges have also been used to generate chemical ionization (CI) plasmas in both negative and positive ion mode with good detection limits (low picogram) and reduced fragmentation at pressures ranging from 1 torr to atmospheric pressure. Introduction systems for glow discharge analysis have also been investigated quite extensively. Air sampling via a thin aperture has been used for the analysis of TNT in the negative ion mode with high sensitivity $(0.4 \mathrm{pg})$ at a sampling rate of $5 \mathrm{mI} / \mathrm{s}$ [32]. Samples can also be deposited on a probe, although in this case thermal desorption rather than sputtering or fast-atom bombardment-type ejection of ihe sample from the probe surface controls the sample concentration in the plasma [33]. Nebulized liquid chromatographic effluents, using helium as drift gas followed by atmospheric pressure ionization [34, 35], have also been analyzed and have been used to demonstrate the versatility of the technique. In general, the mass spectra obtained with glow discharge ionization are of the CI-type, showing adducts, protonation, and some fragment ions. However, despite the numerous analytical applications cited above, only a few studies have probed (1) the effect of the different source parameters on ionization, (2) the bchavior of the organic analytes in the discharge, or (3) the relative contribution of the ionization mechanisms. Parameters such as the sampling distance (interelectrode spacing), source pressure, discharge current and voltage, and the nature of the discharge gas used have important effects on the signal intensity and quality. The use of a rare gas as a discharge gas makes the technique compatible with gas chromatography (GC) as well as with capillary liquid chromatography (LC) if the liquid effluent is vaporized and used as a discharge gas. The present work focuses on organic analysis. It describes and discusses the construction and operation of a direct current glow discharge ion source suitable for GC or LC operation. It also discusses the effects of the different glow parameters mentioned above on analyte signal and rationalizes the probable ionization processes occurring in the source.

\section{Experimental}

All experiments were performed using an upgraded Kratos MS-9 mass spectrometer (Kratos Analytical, Ramsey, NJ) connected to a VG ZAB console (VG Analytical, Manchester, UK). Some modifications have been made to the original instrument because it had not been designed to accept large amounts of gas. Two diffusion pumps (total of $225 \mathrm{~L} / \mathrm{s}$ ) were added to the source housing in addition to an E2-M2 roughing pump (Edwards, West Sussex, UK) connected to the glow discharge source itself. Despite these additions, the pressure in the housing sometimes reached $2 \times 10^{-4}$ torrs during operation and the accelerating voltage was kept at $4 \mathrm{kV}$ to prevent source arcing. A vacuum lock (from a VG 12-12 mass spectrometer) oriented in the beam axis has also been added to the source flange to introduce the probe in the high vacuum system. The direct current discharge was obtained by using a homemade 1450 VDC variable power supply floating at the accelerating voltage. Beam centering and " $\mathrm{z}$ " focusing plate controls, required by the use of a small circular aperture in the source, have been added in the source region with no other modifications to the VG ZAB console. Calibration of the instrument was achieved with a very small quantity of perfluorokerosene (Pfaltz. and Bauer, Waterbury, CT) injerted in the argon line. During the optimization experiments, the sample (butylbenzene) was placed in a temperature controlled vial to maintain a constant vapor pressure, and hence, a constant flow rate of the analyte through a $150 \mu \mathrm{m}$ i.d. $\times 360 \mu \mathrm{m}$ o.d. quartz capillary (Polymicro Tech., Phoenix, AZ) inserted in the moveable cathode. The discharge gases used in this work were those employed for GC (zero grade, Cryo Gaz, Montreal, Canada), and no specific trap was added on the gas line. All chemicals were purchased from Aldrich Chemical Co. (Milwaukee, WI). The pressure in the source was measured with a Baratron gauge (MKS Instruments Inc., Andover, MA) and could be controlled between 0.4-1.2 torr with argon flow rates of $0.5-1 \mathrm{~mL} / \mathrm{min}$. During all experiments the source was kept at $150{ }^{\circ} \mathrm{C}$ to avoid organic deposits. Sensitivity studies were conducted, using a splitless GC injector installed on the argon line, by injecting different gaseous concentrations of the analyte. When a liquid effluent was used, a stainless-steel tubing, $0.72 \mathrm{~mm}$ o.d. $\times 0.43 \mathrm{~mm}$ i.d. (Small Parts Inc, Miami, FL), containing a $15 \mu \mathrm{m} \times 60 \mathrm{~cm}$ quartz capillary was resistively heated by a homemade $10 \mathrm{~V}$ (100 watts) power supply floated at the cathode potential to provide good vaporization of the sample. A Rheodyne $7125 \mathrm{LC}$ injector (Cotati, CA) connected to a high pressure syringe pump, Pheonix-20 (Carlo-Erba Str., Milano, Italy), 
operated at a flow rate of $3.1 \mu \mathrm{L} / \mathrm{min}$ (70:30, $\mathrm{CH}_{3} \mathrm{CN} / \mathrm{H}_{2} \mathrm{O}$ ) was used for the introduction of the samples. In this case, the evaporated mobile phase was used as discharge gas. Mass spectra were recorded at a resolution of 2000 ( $10 \%$ valley) and a scan speed of $10 \mathrm{~s} /$ decade using a Kratos DS-90 data system. The Langmuir probe measurements were conducted in a t-shaped Pyrex glass discharge tube similar in dimensions to those of the source cell, in which a thin brass cylinder could be inserted as anode. The probe, which was inserted through the side of the glass cylinder, is composed of a copper wire $3 \mathrm{~mm}$ long by 0.25 $\mathrm{mm}$ diameter and was placed in the center of the glow, on the discharge tube axis. The whole arrangement is similar to the one of Fang and Marcus [36], except that

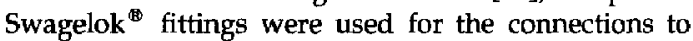
the discharge tube. The direct current voltage for the Langmuir probe was provided from serial combinations of $22.5 \mathrm{~V}$ batteries, and the probe current was measured with a Keithley 485 picoammeter. For the Langmuir probe measurements, the discharge was obtained by using the same homemade power supply used for our glow discharge source on the mass spectrometer.

\section{Results and Discussion}

\section{Glow Discharge Source}

The glow discharge source used in this work was designed to fit a Kratos MS-9 mass spectrometer and is illustrated in Figure 1. It comprises a moveable cathode and a fixed extraction anode placed at both ends of a cylindrical Pyrex glass cell. The cathode is made of a $998^{\circ 0}$ al umina tube (McDanel Refractory, Beaver Falls, PA) into which is inserted a stainless-steel capillary ended by a copper disk joined to the ceramic by Torr-Seal ${ }^{\text {a }}$ epoxy resin (Varian, Lexington, MA). The conical sampling anode is made from commercial brass. It has a sampling hole $(0.4 \mathrm{~mm}$ dia.) drilled in the flat surface which is $5 \mathrm{~mm}$ in diameter with a thickness of $0.25 \mathrm{~mm}$. The size of the hole was chosen such as to

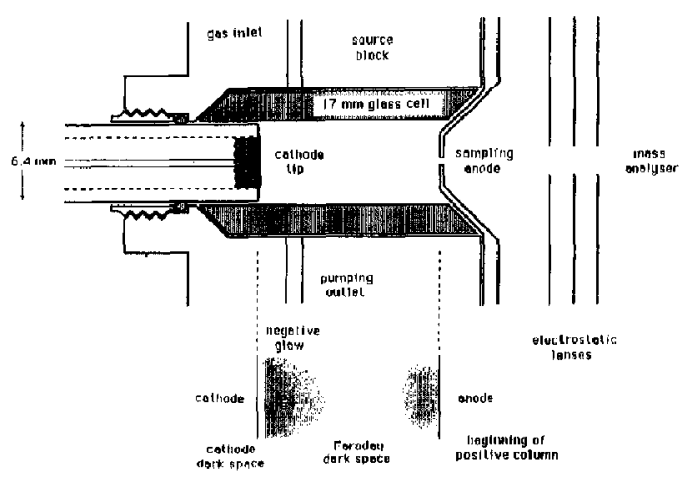

Figure 1. Schematic of the glow discharge ion source. limit its conductance to maintain, under normal operating conditions, the pressure in the source at around 1 torr. The whole source assembly has been adapted to the quartz pillars of the original source. In addition, a gas inlet, and a roughing pump outlet have been added to the glass cell to control the source pressure when a liquid effluent was introduced into it. The purpose of the glass cell is to provide a linear and axially symmetrical discharge between the electrodes to sample the different regions of the glow, which are also shown in Figure 1. By moving the cathode closer to the anode from $17 \mathrm{~mm}$ to $0 \mathrm{~mm}$, it is possible to sample the plasma until the glow extinguishes. The choice of axial sampling was based on studies of charge $[9,19,37]$ and metastable [38] radial distributions in glow discharges, showing that molecular species were found in higher concentrations at some distance from the cathode and from the walls. It also considerably simplifies the source construction and alignment and the interpretation of the results by eliminating discharge asymmetry and problems related to inhomogeneous sampling as the discharge conditions are changed. With this arrangement, the surface of the cell takes a negative potential (wall potential) [20] that reflects the secondary electrons back into the glow, which may increase the ionization efficiency.

\section{Operating Parameters}

Electrical. The effect of the discharge current and voltage on ionic species present in the glow will be discussed further on. However, because the currentvoltage relationship depends on factors such as the nature of the cathode and the discharge gas, (Townsend's factors), pressure, tube geometry, and distance between electrodes [39], it is difficult to directly compare one source to another and each design will have its own characteristics. A breakdown potential (Paschen type) curve obtained at a pressure of 1 torr is shown in Figure 2. It shows a minimum sparking potential that depends on the factors mentioned previously and also on small amounts of impurities present which can drastically change the sparking values, as was observed in these experiments. This minimum indicates the position of a virtual anode [20] and roughly corresponds to the tailing of the negative glow. However, the abscissa on Figure 2 cannot illustrate $p \times d$, as is the case in typical Paschen curves, because the relatively small dimensions of the source restrict the discharge to a certain volume and may not leave enough room for the negative glow at low pressure. The current-voltage dependence is illustrated in Figure 3 for argon pressures of 1.5, 1.0, and 0.5 torr and an interelectrode spacing of $15 \mathrm{~mm}$. As shown on the graph, the current increases rapidly with the applied voltage. This current-voltage characteristic indicates that a cathodic saturation occurs at very low applied voltages. Under these conditions the discharge is called "abnormal" and is usually employed for inorganic 


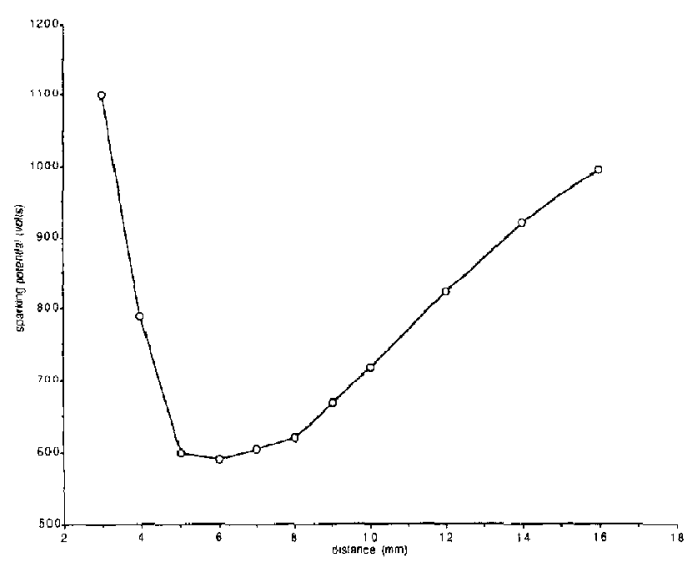

Figure 2. Breakdown potential with distance at a pressure of 1 torr (argon).

analysis in sputtering devices. However, the ranges in currents $(20-200 \mu \mathrm{A})$ and pressures $(0.5-1.5$ torr) used in this work do not favor cathodic sputtering and heating and, under normal operating conditions, the signal for copper (cathode material) was either absent or extremely weak.

Sampling distance. To evaluate the ionic distributions in the discharge, a $17 \mathrm{~mm}$ longitudinal cut of the plasma was made and the results are shown in Figure 4. The intensities for a few important plasma ions are plotted against the distance between electrodes. In these experiments the anode acts as a sampling probe and its position in the glow does not significantly affect the glow itself [40]. As can be seen on the graph, the plasma is not homogenous because singly and doubly charged argon ions are found closer to the cathode. On the other hand, molecular species are found in the tailing of the negative glow where there

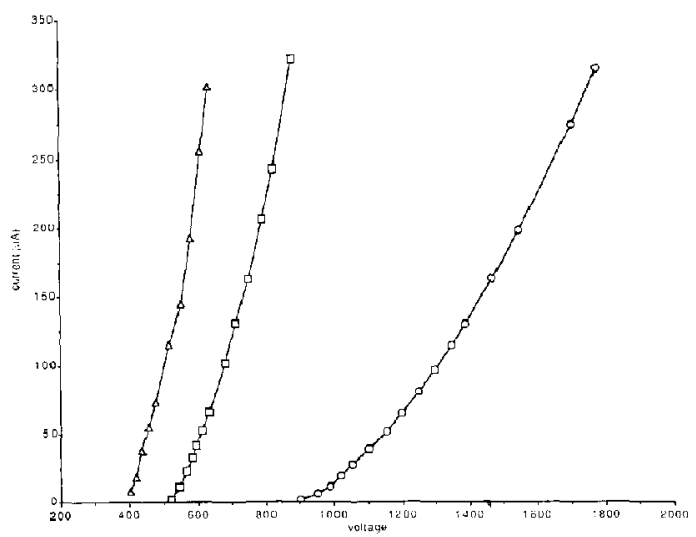

Figure 3. Current-voltage dependence in argon at different pressures; $0: 0.5$ torr; $\square: 1.0$ torr; $\Delta: 1.5$ torr.

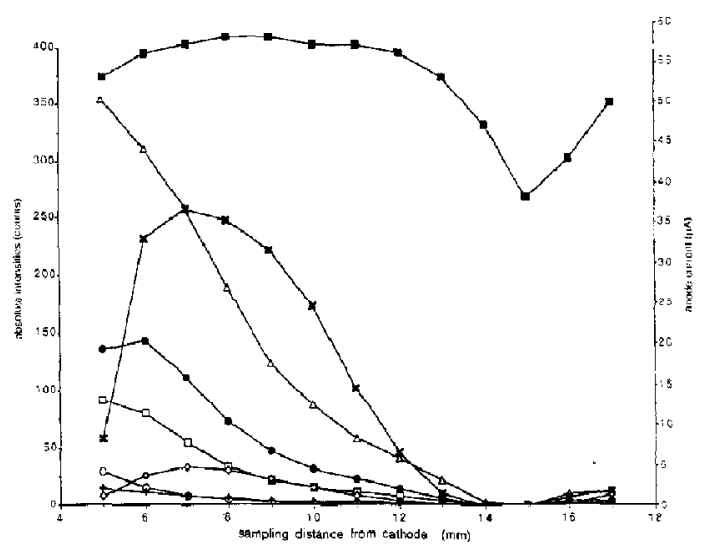

Figure 4. Axial sampling of the argon discharge at a pressure of 1.0 torr; $\mathrm{O} \mathrm{Ar}_{2}^{+} ; \square: \mathrm{ArH}^{+} ; \Delta: \mathrm{Ar}^{+}: \diamond: \mathrm{O}_{2}^{+} ;+: \mathrm{Ar}^{++} ; \mathrm{X}: \mathrm{H}_{3} \mathrm{O}^{+}$; - $\mathrm{H}_{2} \mathrm{O}^{+} ; \mathrm{a}$ : discharge current along the axis at constant voltage.

are fewer high energy particles. Here the molecular species are more likely to remain intact (the cathodic edge of the glow corresponds approximately to where the argon ions are the most abundant). These results agree well with those of Knewstubb and Tickner [41, 42], which were obtained by using a glass sampling probe with a $90^{\circ}$ discharge-sampling geometry. The uneven ionic distributions can only be partially explained by differences in ion mobilities in the glow because $\mathrm{Ar}^{+2} \mathrm{Ar}^{+}$, and $\mathrm{Ar}_{2}^{+}$, which have different mobilities, show quasicoincident maxima. This has also been reported by Knewstubb and Tickner. In fact, the high energy electrons that enter the negative glow lose kinetic energy by successive collisions, with neutrals producing initially doubly and singly charged species and then excited argon atoms. Thus, higher ionization states of argon should be observed closer to the cathode dark space at the edge of the negative glow, but this sets the cone into the cathode fall, thus, inhibiting the ion extraction efficiency and reducing the recorded signal. In this region, the high energy electrons can also fragment the molecular species by electron impact, which would explain the absence of the latter. Furthermore, the presence of charge exchange reactions of low cross sections between different atoms when the energy excess is large is more probable between atoms and molecules because the latter can undergo dissociative ionization. It should be noted that from this position on a further decrease of the interelectrode distance finally extinguishes the discharge. The discharge current flowing through the cell at constant voltage along the axis is also shown in Figure 4. From the graph, it can be seen that the relation between discharge current and ion formation is rather complex. However, because the anode can only collect the slow electrons from the discharge located within a volume of a few Debye lengths in radius, the shape of the current curve already gives an idea of the relative electron density at different sam- 
pling positions. Also, because the ion intensity curves do not match the current curve, it can therefore be assumed that the mean kinetic energy of electrons rather than their number controls ionization in the discharge and that the electrons in the negative glow tailing must have a mean energy a lot lower than the ionization potential of argon, as already reported by Knewstubb and Tickner [41]. The variation of plasma composition with pressure and sampling position is summarized in Table 1. The plasma compositions are given as the percentage of the total ion current collected at distances corresponding to the maximum intensity for $\mathrm{Ar}^{+}$and $\mathrm{H}_{3} \mathrm{O}^{+}$, respectively. Important variations are observed resulting from the different ionization processes along the discharge axis. The presence of the intense water peaks (its relative concentration in the bulk discharge gas being in the order of 10 ppm) has already been studied by Lindeger [43]. The ion at $m / z 18$ is first produced by charge exchange reaction of water with $\mathrm{Ar}^{+}$(reaction 1), and $m / z 19$ is a result of either proton transfer from $\mathrm{ArH}^{+}$or ion-molecule reactions of the water species. The sequence of reactions 2 and 3 is thought to be the most important process leading to the formation of $\mathrm{m} / \mathrm{z} 19$ in these systems. Reaction 4 is also a probable process but, because the concentration of $\mathrm{H}_{2} \mathrm{O}$ is low, production of $\mathrm{H}_{3} \mathrm{O}^{+}$by this pathway is less probable and can be neglected.

$$
\begin{aligned}
& \mathrm{Ar}^{+}+\mathrm{H}_{2} \mathrm{O} \rightarrow \mathrm{Ar}+\mathrm{H}_{2} \mathrm{O}^{+}\left(\mathrm{k}_{1}\right) \text { Charge exchange } \\
& \mathrm{Ar}^{+}+\mathrm{H}_{2} \mathrm{O} \rightarrow \mathrm{ArH}^{+}+\mathrm{OH}^{-}\left(\mathrm{k}_{2}\right) \\
& \mathrm{ArH}^{+}+\mathrm{H}_{2} \mathrm{O} \rightarrow \mathrm{H}_{3} \mathrm{O}^{+}+\mathrm{Ar}\left(\mathrm{k}_{3}\right) \\
& \mathrm{H}_{2} \mathrm{O}^{+}+\mathrm{H}_{2} \mathrm{O} \rightarrow \mathrm{H}_{3} \mathrm{O}^{+}+\mathrm{OH}^{+}\left(\mathrm{k}_{4}\right)
\end{aligned}
$$

\begin{tabular}{|c|c|c|c|c|}
\hline \multirow[t]{2}{*}{ Ion } & \multicolumn{2}{|c|}{$\begin{array}{c}\operatorname{TIC}^{\circ}(0.5 \text { torr }) \\
(\%)\end{array}$} & \multicolumn{2}{|c|}{$\begin{array}{c}\operatorname{TIC}^{a}(1.5 \text { torr }) \\
(\%)\end{array}$} \\
\hline & $\overline{A r^{+b}}$ & $\mathrm{H}_{3} \mathrm{O}^{+c}$ & $\mathrm{Ar}^{+\mathrm{b}}$ & $\mathrm{H}_{3} \mathrm{O}^{+\mathrm{c}}$ \\
\hline $\mathrm{Ar}_{2}^{+}(m / 280)$ & 3.2 & 1.1 & 3.9 & 0.7 \\
\hline $\mathrm{ArH}^{+}(m / z 41)$ & 9.8 & 6.6 & 12.5 & 5.6 \\
\hline $\mathrm{Ar}^{+}(m / 240)$ & 56.2 & 42.4 & 48.6 & 25.0 \\
\hline $\mathrm{O}_{2}^{+}(m / z 32)$ & 1.2 & 2.4 & 1.2 & 6.6 \\
\hline $\mathrm{NO}^{+}(\mathrm{m} / \mathrm{z} 3 \mathrm{O})$ & 1.8 & 2.9 & 1.8 & 2.0 \\
\hline $\operatorname{Ar}^{+2}(m / 220)$ & 3.2 & 1.6 & 1.7 & 0.7 \\
\hline $\mathrm{H}_{3} \mathrm{O}^{+}(m / z$ 19) & 6.7 & 26.5 & 13.2 & 47.3 \\
\hline $\mathrm{H}_{2} \mathrm{O}^{+}(\mathrm{m} / \mathrm{z} 18)$ & 15.7 & 14.7 & 15.4 & 10.4 \\
\hline
\end{tabular}

Ion distribution measurements have been repeated at 1.3 torr (Figure 5 ) in the presence of gaseous butylben-

Table 1. Plasma composition at pressures of 0.5 and 1.5 torr

${ }^{a}$ TIC $=$ total ion current.

'Sampling distance corresponds to the distance of maximum intensity for $\mathrm{Ar}^{+}$.

'Sampling distance corresponds to the distance of maximum intensity for $\mathrm{H}_{3} \mathrm{O}^{+}$. zene (concentration $<100 \mathrm{ppm}$ ) in the discharge gas to evaluate the effect of plasma composition on the behavior of organic compounds. The results obtained indicate that intense protonation $(m / z 135)$ occurs in the negative glow tailing, as was observed with water. Higher energy processes such as charge exchange, Penning transfer or EI may also occur and are indicated by the presence of the molecular and the fragment ions. As expected, the signals at $m / z 92$ and 91 increased when the sampling occurred closer to the cathode. The molecular ion $(m / z$ 134) also follows this pattern, showing that the molecular species can be produced more efficiently in this region, but with higher internal energy resulting from collisions with electrons of higher velocities leading to fragmentation. In the discharge, low energy processes are represented by the ions at $m / z 135$ formed as a result of proton transfer and the ion at $m / z 57$, which is produced by the fragmentation of $m / z$ 135. Among the possible CI reagents present in the discharge, $\mathrm{ArH}^{+}$(concentration up to $25 \%$ that of $\mathrm{Ar}^{+}$at 1.5 torr) and $\mathrm{H}_{3} \mathrm{O}^{+}$(up to twice that of $\mathrm{Ar}^{+}$) may be noted but relatively high pressure and long residence time in the nearly field-free negative glow also make self-protonation a probable process. Very few ions are formed by collision with electrons in the Faraday dark space because the latter have lost most of their kinetic energy by successive collisions and a large proportion of them $(75-95 \%)[2,23]$ are slow electrons $(0.2-1.0 \mathrm{eV})$. The production of metastable atoms in this region of the glow must also decrease, resulting in a lower production of molecular ionic species. This is illustrated in Figures 4 and 5 for distances between 14 and $16 \mathrm{~mm}$. The small increases in intensities observed on the right-hand side of the graphs coincide with the heginning of a red positive column or a striation being separated from the negative glow by a dark space.

To compare the ion distribution curves obtained by ion sampling (Figure 4) with another plasma measurement technique, Langmuir probe experiments have

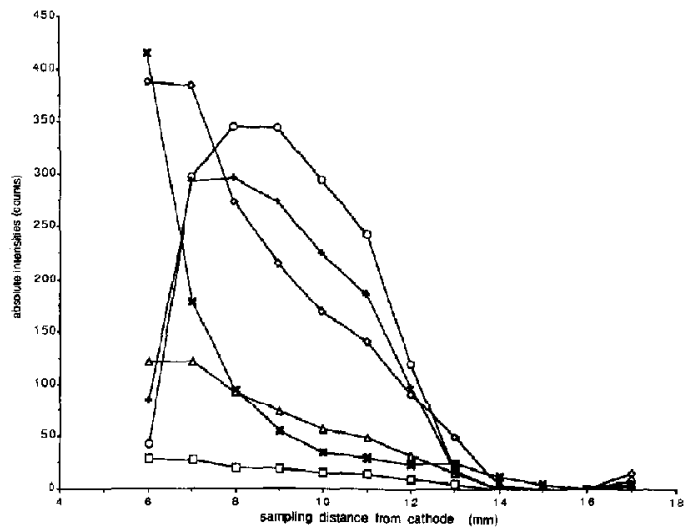

Figure 5. Axial distribution of ions of butylbenzene in the argon discharge at 1.3 torr and $60 \mu \mathrm{A} ; \mathrm{O}: \mathrm{C}_{10} \mathrm{H}_{15}^{+} ; \square: \mathrm{C}_{10} \mathrm{H}_{14}^{+} \Delta$ : $\mathrm{C}_{7} \mathrm{H}_{8}^{+} ; \diamond: \mathrm{C}_{7} \mathrm{H}_{7}^{+} ; \times: \mathrm{Ar}_{2}^{+} ;+: \mathrm{C}_{4} \mathrm{H}_{9}^{+}$. 
been conducted in the glow for various discharge conditions and distances from the cathode. Probe current-voltage characteristic curves obtained with and without the glass cell are shown in Figure 6 for a sampling distance of $5 \mathrm{~mm}$ from the cathode at a discharge current of $75 \mu \mathrm{A}$ and a pressure of 1.04 torr. The results obtained in these experiments show the characteristic shapes similar to those obtained by Ball [44] and Cox et al. [45] but the curves are shifted to lower probe potentials probably because of the small inner diameter of the discharge tube. The experimental data were processed according to the previous references and led to calculated electron temperatures of $2.2 \mathrm{eV}$ and $0.48 \mathrm{eV}$ for the curves in Figure 6 with the discharge operated with and without the glass cell, respectively. As in ref 44, second electron temperature distributions were also present, superimposed on the first ones, showing electron temperatures of $9.8 \mathrm{eV}$ and $5.2 \mathrm{eV}$. They were of less importance, carrying $13 \%$ and $4.9 \%$ of the total current to the Langmuir probe, respectively. The differences in the values of $2.2 \mathrm{eV}$ and $0.48 \mathrm{eV}$ can be explained by the small dimensions of the discharge tube that makes the Langmuir probe to be very close to the walls of the glass cell and to the region where a radial field exists in the discharge (on the order of $10-15 \mathrm{~V}$ for this setup $[19,20]$ ). Also, the higher voltages required to sustain the discharge in the setup containing the glass cell (some $100 \mathrm{~V}$ have to be added) may affect the drift velocities of the particles in the discharge.

A more complete mapping of the plasma is presented in Figures 7 and 8 , which show the effect of current and pressure on important parameters. The results in these figures are presented for the discharge without the glass cell because, in this case, probe measurements were not always feasible because the probe suddenly became the anode when approaching plasma potential. Although the absolute values of elec-

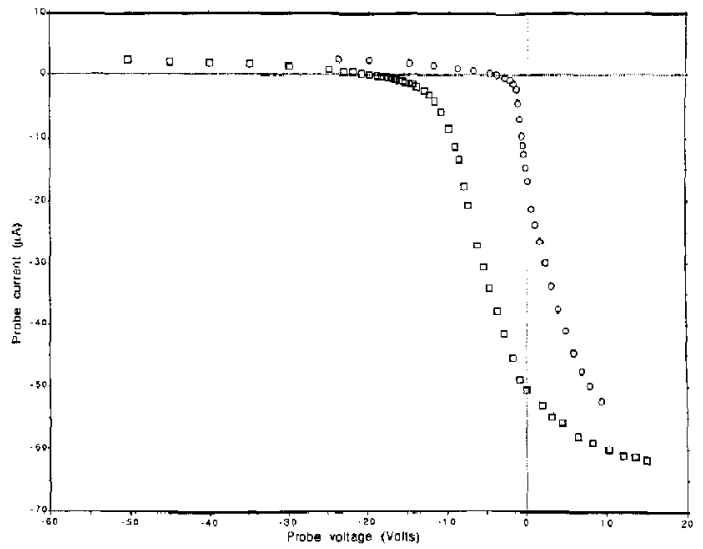

Figure 6. Typical Langmuir probe characteristics obtained tor the argon discharge at a distance of $5 \mathrm{~mm}$ from the cathode, 75 $\mu \mathrm{A}$, and 1.04 torr. $\square$ : with the glass cell; $O$ : without the glass cell.

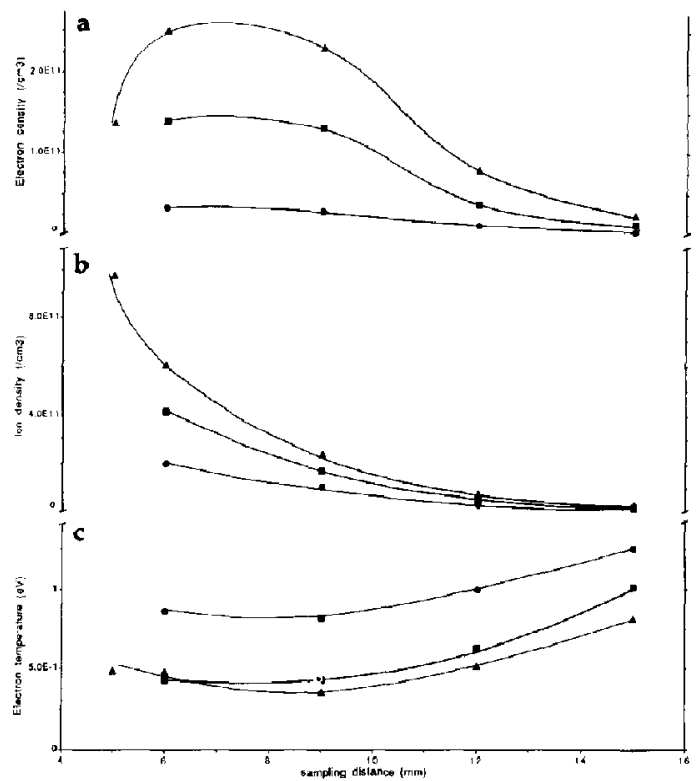

Figure 7. Effect of current on plasma parameters along the discharge axis at a pressure of 1 torr. (a) Electron density: 25 $\mu \mathrm{A} ; \mathrm{\square}: 50 \mu \mathrm{A} ; \Delta: 75 \mu \mathrm{A}$; (b) Ion density: $: 25 \mu \mathrm{A} ; \mathbf{\square}: 50 \mu \mathrm{A}$; $\Delta: 75 \mu \mathrm{A}$; (c) Electron temperature: $25 \mu \mathrm{A}$; : $50 \mu \mathrm{A}$; : $: 75$ $\mu \mathrm{A}$.
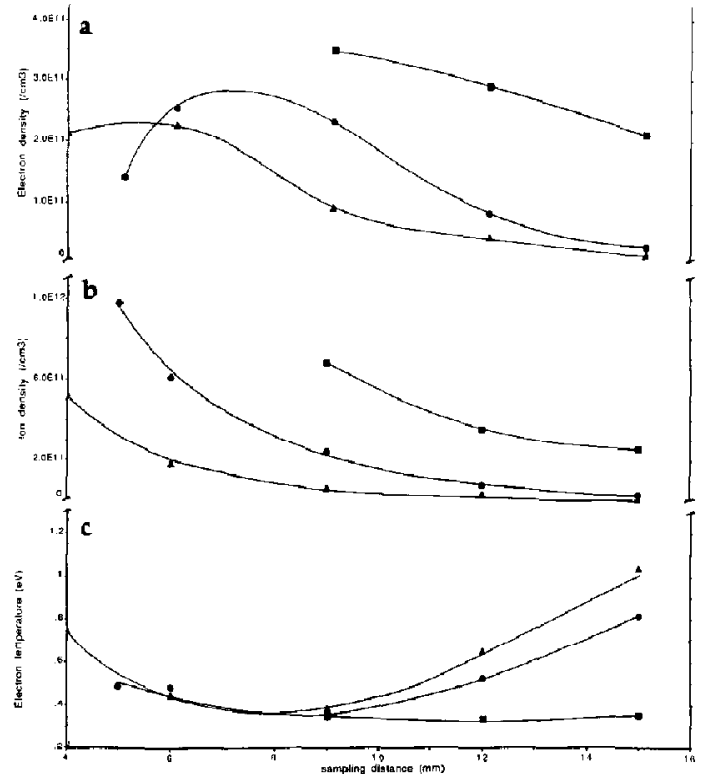

Figure 8. Effect of pressure on plasma parameters along the discharge axis at $75 \mu \mathrm{A}$. (a) Electron density: $\$: 1.5$ torr; 1.0 torr; घ: 0.5 torr; (b) Ion density; $\Delta: 1.5$ torr; 1.0 torr; $\mathbf{\square}: 0.5$ torr; (c) Electron temperature: $\wedge: 1.5$ torr; 1.0 torr; $\mathbf{a}: 0.5$ torr. 
tron temperature would be different from one setup to another, it is expected that the ion and electron densities would not be greatly affected and the effects of the source current and pressure along the discharge axis would be similar. Figure 7 shows the effect of current on electron temperatures (c) and electron (a) and ion (b) densities along the sampling axis at a pressure of 1 torr. The overall effect of current on the density curves is similar in all cases. When more power is dissipated in the discharge, more charged species are produced, giving rise to space-charge sheets (normal glow discharge) and also to local thermalization of species. In general, results obtained with our discharge device agree well, and show similar trends to those of Fang and Marcus [36] who have already discussed the subject in depth. In this work, Langmuir probe measurements were compared to ion distributions measured by ion sampling of Figures 4 and 5 to assess the importance of EI in the production of positive ions in the discharge. As stated before, the function of the anode is not very different from that of a probe [40], and this can be seen by comparing the shape of the curves of current along the axis for Figures 4 and $7 \mathrm{a}$ $(50 \mu \mathrm{A})$. Also, the ion density curve on Figure $7 \mathrm{~b}$ at constant discharge current can be compared to the total ion distributions (not shown) of Figures 4 and 5 . They both show a decrease when sampling is made farther from the cathode, suggesting that the anodic ion sampling is most probably representative of the axial ion distribution in the glow. The marked decrease of ion densities along the discharge axis can be explaincd by ion diffusion and recombination at the walls and in the glow but also by underestimation in the calculation of their number. As shown in Table 1 and Figure 4, the plasma composition is not constant along the axis and, so, calculations of ion densities should be made with the averaged mass instead of the mass of argon. As an example of this, the average mass of ions in the glow is $34.6 \mathrm{Da}$ at $5 \mathrm{~mm}$ and $28.6 \mathrm{Da}$ at 7 $\mathrm{mm}$ from the cathode. Because an ion mass of $40 \mathrm{Da}$ was assumed for the calculations, it would give an underestimation of ion density by $7.5 \%$ at $5 \mathrm{~mm}$ but as much as $18.2 \%$ at $7 \mathrm{~mm}$. Nonetheless, even with the proper correction, the ion densities would still decrease faster than the electron density despite the fact that the electron temperature increases with the distance (Figure $7 \mathrm{c}$ ). This was also reported by Fang and Marcus [36] and as yet has not been explained. The production of argon ions from the ground state by $\mathrm{EI}$ is important only at a short distance from the cathode, while excited argon atoms are produced and ionized at a greater distance by collision with slower electrons [20]. Stable organic ions are also formed at a greater distance (Figure 5) where the electrons have already lost most of their kinetic energy after going through the cathode fall (ref 41 and Figure 7c). After studies by Hess and co-workers [21] on metastable argon quenching by methane, it is thought that reaction by Penning transfer is an important source of organic ions and radicals ( $\mathrm{PPCH} \mathrm{CH}_{4}=14.5 \mathrm{eV}$ ). Radicals have also been observed by molecular spectroscopy by Schüler and Lutz [46] when introducing aromatic hydrocarbons in the glow discharge as the result of thermal activation. In the case of butylbenzene, molecular ions and fragments can be formed by Penning transfer with internal energies up to $3 \mathrm{eV}$ (IP $\mathrm{C}_{10} \mathrm{H}_{14}=8.69 \mathrm{eV}$ [47] and $\mathbf{E}\left(\mathrm{Ar}{ }^{*}\right)=11.55$ and $\left.11.72 \mathrm{eV}[13]\right)$. However, the relative contribution of the Penning transfer to the total ionization process cannot be quantitatively measured because the population and distribution of metastable atoms could not be measured in this work.

The effect of pressure on ion and electron densities is illustrated in Figure 8 . The pressure was varied from 0.5 to 1.5 torr at a constant discharge current of $75 \mu \mathrm{A}$. As expected, the increase in pressure increased the rate of recombination and, so, decreased both the ion and electron current flowing to the probe. It also narrows the dark space adjacent to the cathode as seen by the displacement of the maximum in Figure 8a. Its effect over the electron temperature is not fully understood, but the shape of the curves on Figure $8 \mathrm{c}$ can be explained by the fact that all the regions of the glow are stretched when decreasing the source pressure so the displacement of the minimum of the curve is observed. The elevation of the electron temperature observed on the right-hand side of the graph is an indication of the presence of weak potential gradient in the Faraday dark space. Although the total ion density appears to be lower for higher pressures, it will be seen later on that high pressure has a favorable effect because it promotes the formation of parent-molecular ions.

\section{Mass Spectrometric Study of the Effects of Source Pressure and Current}

An extensive mapping of ionic distribution is presented in Figures 9 to 11 . Figure 9 shows the effect of source pressure on the intensity of the $(\mathrm{M}+\mathrm{H})^{+}$and $\mathrm{M}^{+}$ions as a function of the sampling distance. The data show that an increase in source pressure, increases the protonation efficiency $(\mathrm{M}+\mathrm{H})^{+}$. On the other hand, the $\mathrm{M}^{+}$ion is not really affected by higher pressures, suggesting that electron ionizaton is not the only process that leads to its production. The increase in pressure also reduces the thickness of the cathode fall sheath, decreasing the optimum sampling distance for a selected species. In our experiments the use of higher pressures was not desirable because of the poor pumping efficiency of the source housing, giving rise to arcing problems. The combined effects of current and voltage on ion intensities are shown in Figure 10 where the absolute intensities of some selected ions in butylbenzene are reported as a function of the discharge current at a constant sampling distance. The graph shows that a small current of $40 \mu \mathrm{A} \quad(0.5$ $\mathrm{mA} / \mathrm{cm}^{2}$ ) is sufficient to ionize and fragment the compound. The use of a higher current in the discharge 


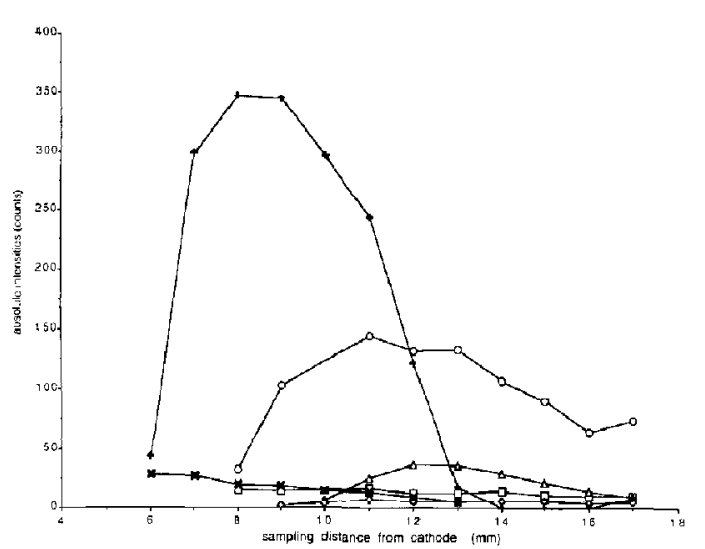

Figure 9. Effect of source pressure on distribution of ions from butylbenzene in argon at $60 \mu \mathrm{A} ;+, \mathrm{O}, \Delta: \mathrm{C}_{10} \mathrm{H}_{15}^{+}$at $1.3,0.65$, 0.35 torr, respectively; $x, \square, 0: \mathrm{C}_{10} \mathrm{H}_{14}^{+}$at $1.3,0.65,0.35$ torr, respectively.

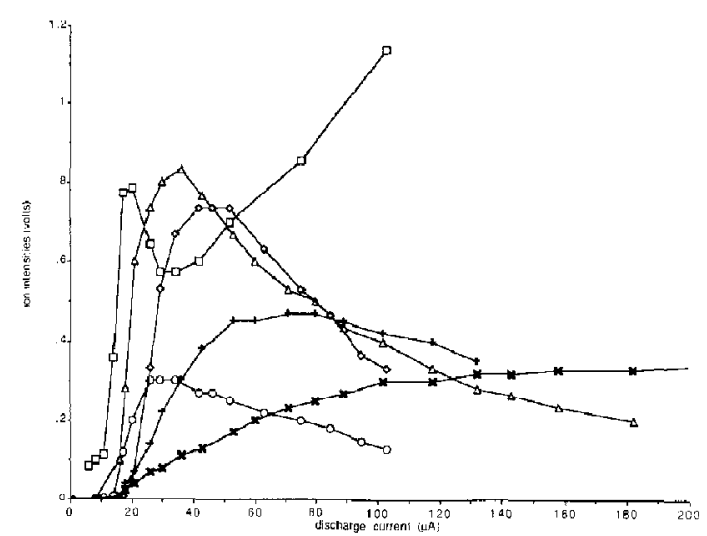

Figure 10. Effect of discharge current on the butylbenzene fragmentation pattern at a sampling distance of $7 \mathrm{~mm} . \diamond: \mathrm{C}_{10} \mathrm{H}_{15}^{+}$ (/3); O: $\mathrm{C}_{10} \mathrm{H}_{14}^{+} \Delta: \mathrm{C}_{7} \mathrm{H}_{7}^{+}(/ 3) ; *: \mathrm{C}_{3} \mathrm{H}_{7}^{+} ; \mathrm{\square}: \mathrm{Ar}^{+}(/ 200) ; \mathrm{X}:$ $\mathrm{CH}_{3}^{+}$. Number in parentheses indicates scaling factors.

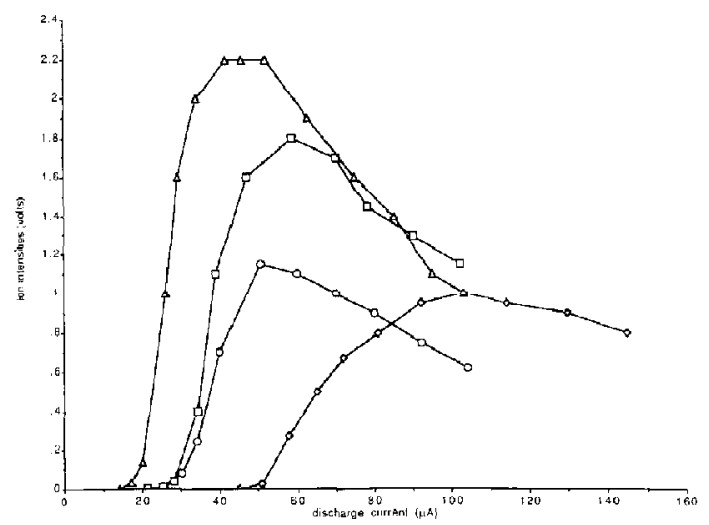

Figure 11. Effect of discharge current on the optimum sampling distance for $\mathrm{C}_{10} \mathrm{H}_{15}^{+}$in argon. $\mathrm{O}: 5 \mathrm{~mm} ; \Delta: 7 \mathrm{~mm} ; \square: 9 \mathrm{~mm} ; 0$ : $11 \mathrm{~mm}$. narrows the cathode fall and stretches the negative glow, thus, any change in the appropriate discharge current requires a modification of the sampling distance to sample back the right region, as shown in Figure 11. Even if the effect of the current on ion intensities is not fully understood, increasing the current increases the electron and the plasma density and also increases the concentration of energetic atomic species such as $\mathrm{Ar}^{2+}$ and $\mathrm{Ar}^{3+} \mathrm{N}^{+}$and $\mathrm{O}^{+}$, thus fragmenting molecular species which results in a loss of signal intensity for $(\mathrm{M}+\mathrm{H})^{+}, \mathbf{M}^{+}$, and other ions at currents over $90 \mu \mathrm{A}\left(1.1 \mathrm{~mA} / \mathrm{cm}^{2}\right)$. The anode sheath potential is also decreased at higher currents, leading to poorer ion extraction efficiencies [20].

\section{Nature of Discharge Gas}

Although the use of discharge gases other than argon or helium would be quite improbable due to their cost, the effect of the nature of the discharge gas has been investigated by using phenylheptane rather than butylbenzene to avoid the interference of xenon at $m / z 134$. The mass spectra obtained with different gases are presented in Figure $12 a-d$ at a pressure of 0.75 torr. It can be observed from Figure 12 that spectra $\mathrm{a}, \mathrm{b}$, and $\mathrm{c}$ show both parent-molecular ions $(\mathrm{m} / \mathrm{z}$ 177) and fragments. The parent-molecular $(\mathrm{M}+\mathrm{H})^{+}$peak increases when using gases of lower ionization potentials and metastable states as well as the ratio of the intensities of peaks at $m / z \quad 92$ and 91, indicating a lower overall internal energy transfer from the discharge to the phenylheptane. It is interesting to note that the intensity of the ion at $m / z 57$, which is a daughter ion of $m / z 177$, follows the same trend as $m / z 92$. When the discharge is operated with Xe some interesting features are observed, as can be seen in Figure 12d. Figure 12d shows that not only is the parent-molecular ion at $m / z 177$ absent with $\mathrm{Xe}$, but also that the fragment ions at $m / z 57$ and 79 have been substantially reduced, indicating a much lower energy deposition in the Xe plasma. This is supported by the intensity ratio of ions at $m / z 92$ and 91 , which is strongly increased with $X_{\mathbf{e}}$, as can be observed in Figure 12d. The absence of the protonated molecule and the corresponding fragments can be explained by the fact that enthalpies associated with reactions 1 and 2 do not favor the production of $\mathrm{XeH}^{+}$and $\mathrm{H}_{2} \mathrm{O}^{+}$, resulting in a poor $\mathrm{H}_{3} \mathrm{O}^{+}$yield. Furthermore, high pressure charge exchange experiments with xenon and argon on some organic molecules that have been conducted in this lab (results not shown) have given mass spectra in which very few or no molecular ions could be observed. This had already been reported by Einolf and Munson [48] and suggest that the molecular ion present in the spectrum obtained with xenon is formed only by the contributions of Penning and EI. Moreover, the phenylheptane molecular ions that could be formed by collisions with the low mean kinetic energy electrons from the negative glow or by Penning transfer 

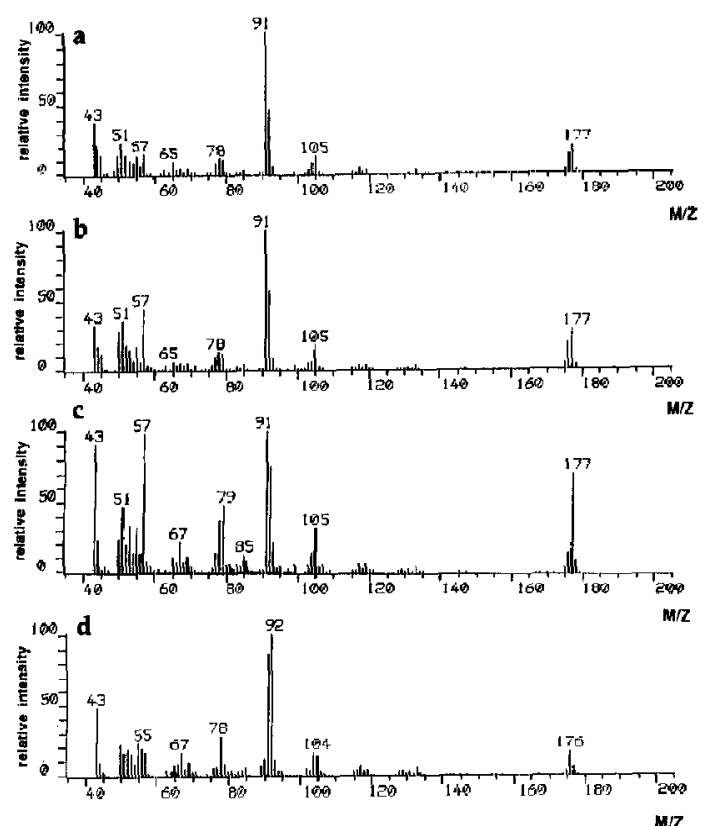

Figure 12. Effect of the nature of the discharge gas on the mass spectrum of phenylheptane. (a) neon; (b) argon; (c) krypton; (d) xenon.

with excited xenon would result in a low internal energy in the ion that would lead to rearrangements rather than fragmentation, as can be seen in the mass spectrum obtained with xenon (Figure 12d). It should be stated that the results presented in Figure 12 have been taken at the distance corresponding to the maximum for the ion at $m / z 177$ in each of the spectra to compensate for the fact that the volume of the plasma is altered as the discharge gas is varied. The use of different discharge gases can thus be revealing in terms of the different processes leading to ion formation and fragmentation that can occur in the glow discharge source.

\section{Liquid Introduction Mode}

The glow discharge source described in this work has also been used to analyze compounds introduced via a liquid mobile phase. Preliminary studies in this mode of operation have been conducted by using caffeine and adenosine in a mixture of $70 / 30 \mathrm{CH}_{3} \mathrm{CN} / \mathrm{H}_{2} \mathrm{O}$. The spectra obtained by injecting samples containing $0.5 \mu \mathrm{g}$ of analytes are presented in Figure $13 \mathrm{a}$ and $\mathrm{b}$. Protonated molecules are observed in both cases, with a few fragment ions being produced for adenosine. In this spectrum, the peak at $m / z 136$ represents the $(\mathrm{B}+\mathrm{H})^{+}$usually present with the thermospray interface. However, the peak at $m / z 134$ has not yet been explained. The experiments conducted in this mode of operation indicate that the parameters studied in this work have similar effects whether the sample is intro-
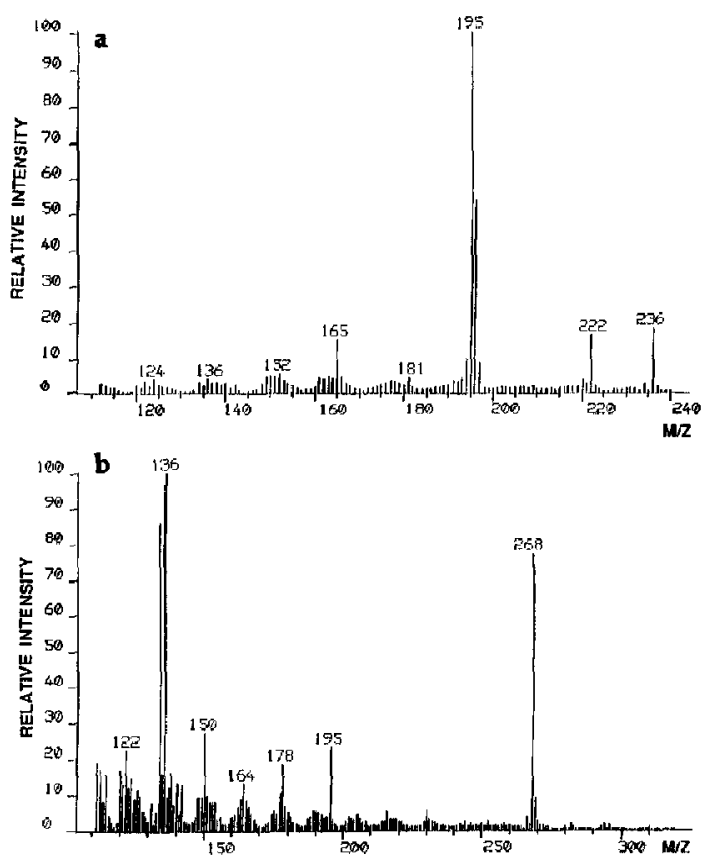

Figure 13. Gluw discharge mass spectrum of (a) $0.5 \mu \mathrm{g}$ caffeine, (b) $0.5 \mu \mathrm{g}$ adenosine in $70: 30 \mathrm{CH}_{3} \mathrm{CN} / \mathrm{H}_{2} \mathrm{O}$.

duced in the gas or liquid phase and that the use of the evaporated liquid as a discharge gas does not essentially alter the general operation of the ion source. However, the use of a liquid-mobile phase is expected to increase the background. Additional investigations are currently underway with the liquid introduction system and they include the operation of the discharge with other solvents to reduce the background signal, especially high in the spectrum of adenosine. The results of these investigations will be published elsewhere.

\section{Spectral and Analytical Features}

To evaluate the analytical potential of the glow discharge ion source for the characterization of organic compounds several typical experiments have been conducted. The results obtained indicate that the spectra generated from the gaseous or liquid introduction of the sample do not differ significantly as they exhibit the same features in terms of parent-molecular peaks and fragment ions. The analysis with gaseous introduction of several compounds belonging to different chemical groups such as alkanes, ketones, and amines reveals that all of these classes of compounds give either $(\mathrm{M}+\mathrm{H})^{+}$or $(\mathrm{M}-\mathrm{H})^{+}$as parent peak when analyzed with Ar and that many fragments are present in the spectra [49]. For all the compounds that have been studied the information content of the glow discharge spectra was higher than those obtained by more conventional ionization techniques such as $\mathrm{EI}$ or $\mathrm{CI}$. 
To provide examples for the comparison of the spectral features observed in glow discharge with those present with other ionization techniques, 2-phenyl1,3-dioxolane ( $\mathrm{MW}=150$ ) was chosen because its spectrum differs substantially from one technique to another. The mass spectra obtained for this analyte using an argon glow discharge and three other common ionization techniques are reported in Table 2 , which gives a mass/intensity list for selected significant ions. As can be seen from Table 2, the glow discharge mass spectrum exhibits peaks in the molecular region accompanied by intense fragments at lower masses. The presence of ions at $m / z 151,150$, and 149 indicates that both high and low energy ionization processes are occurring in the source. This example illustrates quite well the fact that many ionization processes leading to different fragmentation paths occur simultaneously in the discharge as a result that nearly all the fragments found in the three other techniques are also found in the glow discharge spectrum. For example, ions at $m / z 151,107$, and 73 present in the glow discharge spectrum are also observed in the $C I$ data, while ions at $m / z 105,78$, and 77 are present in both the glow discharge and EI spectra and are relatively weak in the CI spectrum. This interesting feature provides extremely useful structural information that must for many types of analytes be otherwise obtained by the use of different techniques such as alternate $\mathrm{FI} / \mathrm{CI}$ (ACE).

Another important analytical feature besides structural information content that has to be considered is the sensitivity associated with this type of source. Despite the low pressure used in this study (1 torr), a fair sensitivity was obtained in measurements made using propylbenzene and 2-heptanone, as shown in Figure 14. For both compounds a slight deviation from linearity was observed that is thought to come from self-protonation and long residence time of the compounds in the source. Detection limits of $100 \mathrm{pg}$ (signal-to-noise > 3) were obtained for a 25-second peak

Table 2. Relative intensities in the spectrum of 2-phenyl, 1-3-dioxolane with several ionization techniques

\begin{tabular}{|c|c|c|c|c|}
\hline $\operatorname{lon}(m / 2)$ & $\mathrm{GD}^{\mathrm{a}}$ & $\mathrm{Cl}^{\mathrm{b}}\left(\mathrm{CH}_{4}\right)$ & $\mathrm{Cl}^{\mathrm{b}}\left(\mathrm{C}_{4} \mathrm{H}_{10}\right)$ & $\mathrm{El}^{\mathrm{G}}$ \\
\hline 151 & 86.8 & 33.3 & 100.0 & 2.3 \\
\hline 150 & 15.1 & 6.6 & 7.5 & 27.3 \\
\hline 149 & 51.9 & 21.4 & 14.6 & 100.0 \\
\hline 119 & 8.0 & 0.9 & 0.0 & 5.6 \\
\hline 107 & 43.4 & 40.0 & 5.7 & 0.0 \\
\hline 105 & 51.9 & 5.2 & 1.4 & 26.4 \\
\hline 91 & 37.7 & 4.3 & 1.9 & 17.9 \\
\hline 79 & 66.0 & 7.6 & 0.6 & 2.8 \\
\hline 78 & 53.8 & 4.3 & 9.9 & 25.5 \\
\hline 77 & 41.0 & 1.9 & 0.0 & 28.3 \\
\hline 73 & 100.0 & 1000 & 18.9 & 6.9 \\
\hline
\end{tabular}

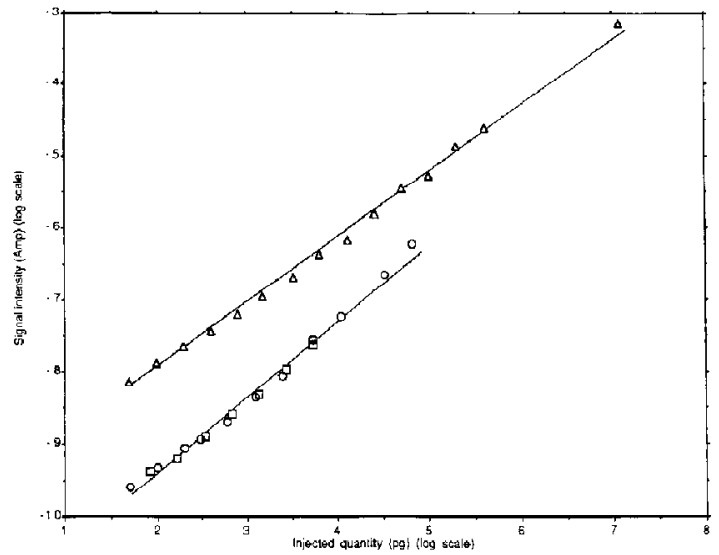

Figure 14. Calibration curve in argon for parent-molecular ions of: $O$ : 2-heptanone; $\square$ : propylbenzene $\left[(\mathrm{M}+\mathrm{H})^{+}\right.$ions]; $\Delta$ : isobutane $\left[(\mathrm{M}-\mathrm{H})^{+}\right.$ion].

width in single ion monitoring of the parent-molecular ion $(\mathrm{M}+\mathrm{H})^{+}$. It is, however, possible to reduce the peak width significantly with a proper injection system, such as those found in GC, and there is no doubt that the detection limits can be reduced to lower picogram levels. To avoid the introduction of a large quantity of solvent in the gas discharge, isobutane was used (Figure 14) to evaluate the linearity of the source signal. It has shown to be linear over at least six orders of magnitude, showing slight curvature, which would make this source a suitable detector for gas chromatographic techniques.

\section{Conclusion}

The results presented in this work indicate that the prototype glow discharge ion source described possesses interesting analytical features and that the parameters leading to ionization and fragmentation can be rationalized in this type of device. In terms of organic compound analysis, the source provides excellent structural information that often surpasses that obtained by EI or CI. Its sensitivity is good and its operation allows the introduction of both gaseous and liquid samples. The ion source has proved to be very resistant to contamination because it has been working for severals months without requiring cleaning or showing significant losses in sensitivity. During this period it was allowed to work with a resolution that could be adjusted between 2000 (flat top) and 5000 (10\% transmission) with a maximum resolution of 7000 at $2 \%$ transmission. It is self-cleaning because reversing the discharge voltage has the effect of bombarding what used to be the anode. Little modification of the cathode design would allow the use of thermal desorption, the most commonly employed technique for routine analysis. It also gives reasonable detection limits and dynamic range and, thus, could casily fit a 
gas chromatograph. Moreover, the spectra obtained show intense fragmentation and parent-molecular peaks that are essential for the identification of some type of organic compounds during routine analysis.

\section{Acknowledgment}

The authors acknowledge the financial support of the Natural Sciences and Engineering Research Council of Canada (NSERC) during this project.

\section{References}

1. Coburn, J. W. Rev. Sci. Instr. 1970, 41, 1219.

2. Coburn, J. W.; Kay, E. Appl. Phys. Letters 1971, 19, 350.

3. Oechsner, H.; Gerhard, W. Phys. Lett. 1972, 40A, 211.

4. Colby, B. N.; Evans, Jr., C. A. Anal. Chem. 1974, 46, 1236.

5. Harrison, W. W.; Magee, C. W. Anal. Chem. 1974, 46, 461.

6. Daughtrey, Jr., E. H.; Harrison, W. W. Anal. Chem. 1975, 47, 1024.

7. Bruhn, C. G.; Bentz, B. L.; Harrison, W. W. Anal. Chem. 1978, $50,373$.

8. Eckstein, E. W.; Coburn, J. W.; Kay, E. Int. J. Mass Spectrom. Ion Phys. 1975, 17, 129.

9. Howorka, F.; Lindeger, W.; Pahl, M. Int. J. Mass Spectrom. Ion Phys. 1973, 12, 67.

10. Bentz, B. L.; Bruhn, C. G.; Harrison, W. W. Int. I. Mass Spectrom. Ion Phys. 1978, 25, 409.

11. Stuewer, D. Fresenius. I. Anal. Chem. 1990, 337, 737.

12. Hess, K. R.; Marcus, R. K. Spectroscopy, 1987, 2.

13. Harrison, W. W.; Hess, K. R.; Marcus, R. K.; King, F. L. Anal. Chem. 1986, 58, 341A.

14. Hecq, M.; Hecq, A.; Fontigny, M. Anal. Chim. Acta, 1983, 155. 191.

15. Hall, D. J.; Robinson, P. K. American Laboratory Aug. 1987.

16. Jabukowsky, N.; Stuewer, D.; Vieth, W. Anal. Chem. 1987, 59, 1825.

17. Cantle, J. E.; Hall, E. F,; Shaw, C. J.; Turner, P. J. Int. I. Mass Spectrom. Ion Pilys. 1983, 46, 11.

18. Loving, T. J.; Harrison, W. W. Anal. Chem. 1983, 55, 1523.

19. Llewellyn-Jones, F. The Glow Discharge; Methuen's Monographs, Worsnop, B. L., Ed. London, 1966.

20. Chapman, B. Glow Discharge Processes; Wiley: New York, 1980.

21. Smith, R. L.; Serxner, D.; Hess, K. R, Anal. Chem. 1989, 61, 1103.

22. Hess, K. R.; Harrison, W. W. Anal. Chem. 1988, 60, 691.
23. Howorka, F.; Pahl, M. Z. Naturforsch. 1972, 27a, 1425.

24. Pahl, M; Lindeger, W; Howorka, F. Z. Naturforsch. 1972, $2 / a, 6 \%$.

25. Yu, T.; Tanabe, K.; Winefordner, J. D. Anal. Chim. Acta 1987., $201,317$.

26. Anderson, D. R.; Bierbaum, V.; Depuy, C. H.; Grabowsky, J. J. Int. J. Mass Spectrom. Ion Phys. 1983, 52, 65.

27. Schneider, B.; Brueur, M.; Hatmann, H.; Budzikiewicz, $H$. Org. Mass Spectrom. 1989, 24, 216.

28. Matsumoto, K.; Kojïma, H.; Yasuda, K.; Tsuge, S. Org. Mass Spectrom. 1985, 20, 243.

29. Hunt, D. F.; McEwen, C. N.; Harvey, T. M. Anal. Chem. 1975, 47,1730 .

30. Scheibel, R. C.; Tanner, O. P.; Wood, K. V. Anal. Chem. 1981, $53,552$.

31. Dzidic, L.; Carrol, D. I.; Stillwell, R. N.; Ilorning, E. C. Attal. Chem. 1976, 48, 1763.

32. McLuckey, S. A.; Glish, G. L.; Asano, K. G.; Grant, B. C. Anal. Chem. 1988, 60, 2220.

33. Mason, R.; Milton, D. Int. J. Mass Spectrom. Ion Proc. 1983, 52,65 .

34. Sofer, I.; Zhu, J.; Lee, H. S.; Antos, W.; Lubman, D. M. Appl. Spectrosc. 1990, 44, 1391.

35. Zhu, J.; Zhao, J.; Lubman, D. M. Anal. Chem. 1992, 64, 1426.

36. Fang, D.; Marcus, R. K. Spectrochimica Acta 1990, 45B, 1053.

37. Howorka, F.; Scherleitner, A.; Gieseke, V.; Kuen, I. Int. I. Mass Spectrom. Ion Phys. 1980, 32, 321.

38. Rajotte, R. J. Can. J. Spec. 1974, 19, 178.

39. Electrical Breakdozan and Discharges in Gases, Kunhardt, E. E,; Luessen, L. H., Eds. Plenum: New York, 1983.

40. Howatson, A. M. An Introduction to Gas Discharge, $2 \mathrm{~d} \mathrm{Ed}$. Pergamon: Oxford, 1976.

41. Knewstubb, P. F.; Tickner, A. W. J. Chem. Phys. 1962, 36, 684.

42. Knewstubb, P. F.; Tickner, A. W. J. Chem, Phys. 1962, 36, 673.

43. Lindeger, W. Phys. Rev. A 1973, 7, 328.

44. Ball, D. J. J. Appl. Phys. 1972, 43, 3047.

45. Cox, T. I.; Deshmukh, V. G. I.; Hope, D. A. O.; Hydes, A. J.; Braithwaite, N. St. J.; Benjamin, N. M. P. J. Phys. D: Appl. Phys. 1987, 20, 820 .

46. Schüler, H.; Lutz. E. Spectrochimica Acta 1957, 10, 61.

47. Harrison, A. G.; Lin, M. S. Int. J. Mass Spectrom. Ion Phys. 1983, 51, 353.

48. Einolf, N.; Munson, B. Int. I. Mass Spectrom. Ion Phys. 1972, 9,141 .

49. Carazzato, D.; Bertrand, M. J. Proceedings of the 40th Annual ASMS Conference on Mass Spectrometry and Allied Topics; Washington, DC, 1992; p 216. 